\title{
Determining Mancozeb Deposition Benchmark Values on Apple Leaves for the Management of Venturia inaequalis
}

\author{
P. Rebel, ${ }^{1}$ C. Poblete-Echeverría, ${ }^{2}$ J. G. van $\mathrm{Zyl}^{3}{ }^{3}$ J. P. B. Wessels, ${ }^{3}$ C. Coetzer, ${ }^{1}$ and A. McLeod ${ }^{1, \dagger}$ \\ ${ }^{1}$ Department of Plant Pathology, Stellenbosch University, Matieland, 7600, South Africa \\ ${ }^{2}$ Department of Viticulture and Oenology, Stellenbosch University, 7600, South Africa \\ ${ }^{3}$ ProCrop, Somerset West, 7130, South Africa
}

\begin{abstract}
Apple scab, caused by Venturia inaequalis, is the most common fruit and foliar disease in commercial apple production worldwide. Early in the production season, preventative contact fungicide sprays are essential for protecting highly susceptible continuously unfolding and expanding young leaves. In South Africa, mancozeb is a key contact fungicide used for controlling apple scab early in the season. The current study developed deposition benchmarks indicative of the biological efficacy of mancozeb against apple scab, using a laboratory-based apple seedling model system. The model system employed a yellow fluorescent pigment that is known to be an effective tracer of mancozeb deposition. A concentration range of mancozeb ( 0.15 to 1 times the registered dosage) and fluorescent pigment concentrations was sprayed onto seedling leaves, which yielded various fluorescent particle coverage (FPC\%) levels. Modeling of the FPC\% val-

benchmark model where $0.40 \%, 0.79 \%$, and 1.35 FPC $\%$ yielded 50,75 , and $90 \%$ apple scab control, respectively. These FPC $\%$ values were higher than the benchmarks $(0.10,0.20$, and $0.34 \mathrm{FPC} \%$, respectively) obtained with quantitative real-time PCR (qPCR) disease quantification. The qPCR benchmark model is recommended as a guideline for evaluating the efficacy of mancozeb sprays on leaves in apple orchards since the TIRI benchmark model underestimated disease control. The TIRI benchmark model yielded $68 \%$ disease control at the lowest mancozeb dosage, yet no visible lesion developed at this dosage. Both benchmark models showed that mancozeb yielded high levels of disease control at very low concentrations; for the qPCR benchmark model the FPC\% value of the $\mathrm{FPC}_{90}$ (90\% control) corresponded to 0.15 times that of the registered mancozeb concentration in South Africa, i.e., $85 \%$ lower than the registered dosage.
\end{abstract} ues versus percent disease control yielded different benchmark values when disease quantification was conducted using two different methods. Thermal infrared imaging (TIRI) disease quantification resulted in a
Keywords: Venturia inaequalis, apple scab, spray deposition, thermal infrared imaging, disease quantification, quantitative real-time PCR
Apple scab, caused by Venturia inaequalis, is the most common fruit and foliar disease in commercial apple production worldwide. The pathogen can cause significant economic losses if not controlled (MacHardy 1996a). Primary pathogen infections are managed using sanitation practices and postharvest fungicide and urea sprays in fall either to trees just prior to leaf drop and/or on leaf litter (Bowen et al. 2011; Holb 2008; MacHardy 1996b). In spring, primary infections, and secondary infections occurring during the growing season must be managed using regular fungicide spray applications; newly unfolded leaves must continuously be protected against the pathogen since they are highly susceptible to infections during the first 3 to 5 days (Bowen et al. 2011; MacHardy and Gadoury 1986). Fungicide sprays must be effective since infection of only a few unprotected leaves can result in the development of destructive epidemics under favorable environmental conditions (MacHardy and Gadoury 1986).

The effectiveness of fungicide spray applications can be evaluated through orchard spray deposition trials and biological efficacy benchmark models (Landers 2010; Van Zyl et al. 2013). Spray deposition trials can assess the level of spray deposition achieved within

Current address of P. Rebel: ProCrop, Somerset West, 7130, South Africa

${ }^{\dagger}$ Corresponding author: A. McLeod; adelem@sun.ac.za

Funding: The South African Apple and Pear Producer's Association (SAAPPA) funded this project.

*The $\boldsymbol{e}$-Xtra logo stands for "electronic extra" and indicates that one supplementary table is published online.

The author(s) declare no conflict of interest.

Accepted for publication 21 July 2019.

(C) 2020 The American Phytopathological Society an orchard based on deposition parameters (quantity and quality) of a tracer of the fungicide (Rossouw et al. 2018; Schutte et al. 2012; Sutton and Unrath 1988; van Zyl et al. 2010, 2013, 2014). Good tracers of fungicide spray deposition are fluorescent pigments, which are more cost-effective than residue analyses. Fluorescent tracers, along with macrophotography and image analyses, also allow for the evaluation of the quality and uniformity of deposition. The latter is not possible when residue analyses are employed (Juste et al. 1990). Biological efficacy benchmark models of deposition are predetermined spray deposition quantity values of a fungicide that are correlated with specific levels of disease control (van Zyl et al. 2013). Only a few benchmark models have been reported. For example, van Zyl et al. (2013) developed a biological efficacy benchmark model for the control of Alternaria brown spot on citrus leaves with copper oxychloride; $50 \%$ and $75 \%$ disease control was achieved at fluorescent particle coverage (FPC\%) of $2.07 \%\left(\mathrm{FPC}_{50}\right)$ and $4.14 \%\left(\mathrm{FPC}_{75}\right)$.

Currently, there is no biological efficacy benchmark model for fungicide spray deposition on apples in South Africa and in other regions of the world for any plant disease. Due to the significant negative effects of apple scab in South Africa and the extensive use of the fungicide mancozeb, this system combined with the SARDI yellow fluorescent pigment will be ideal for developing a biological efficacy benchmark model. The SARDI yellow fluorescent pigment has previously been reported as a good tracer of mancozeb (Rossouw et al. 2018). Mancozeb, an effective broad-spectrum preventative fungicide in the dithiocarbamate chemical class (Gullino et al. 2010), is the main contact fungicide used against apple scab in South African orchards. Depending on the weather conditions, up to 15 sprays may have to be applied per season in South African apple orchards (J. P. B. Wessels, ProCrop South Africa, personal communication).

Challenges with the establishment of a biological efficacy benchmark model for apple scab are twofold; the pathogen does not produce spores abundantly on artificial media, and leaf lesions are diffuse and are thus difficult to quantify accurately. Both of the aforementioned aspects are required for developing a biological efficacy benchmark model (Van Zyl et al. 2013). V. inaequalis produces 
ascospores in its saprophytic stage and conidiospores in its biotrophic stage; both can be harvested from naturally infected orchard leaves for conducting artificial inoculation of leaves (Bowen et al. 2011; Oerke et al. 2011; Parisi and Lespinasse 1996). However, the production of conidiospores on artificial media has the advantage in that it allows for a defined pathogen population to be used in continuous screenings over multiple experiments (Dewdney et al. 2003; Oerke et al. 2011; Parisi and Lespinasse 1996; Parker et al. 1995; Stensvand et al. 1997). Conidiospores can be produced on artificial media using a cellophane plate method described by Parker et al. (1995).

Apple scab lesions on young susceptible leaves can be quantified using a visual rating scale. Visual ratings are based on the area of a leaf covered with visible apple scab lesions on a scale from 0 to $100 \%$ leaf area covered with lesions with increments of $10 \%$ (Parisi et al. 1993; Schwabe 1976, 1979, 1980). A drawback of the visual rating scale is that the accuracy of disease quantification is subject to the opinion and experience of the person conducting the evaluations. Although visible light photography and image analyses with color thresholding is a technique commonly used for disease quantification, this is not feasible for apple scab lesions due to the diffuse nature of artificially inoculated lesions, and poor color contrasts between brown sporulating lesions and dark green leaf tissue (Barbedo 2013).

Accurate alternatives to visual leaf lesion scoring for the quantification of apple scab infections have been identified. These include the use of multi- and hyperspectral reflectance imaging (Delalieux et al. 2007), thermal infrared imaging (TIRI) (Oerke et al. 2011), and real-time quantitative polymerase chain reaction (qPCR) analysis (Daniëls et al. 2012; Gusberti et al. 2012). Oerke et al. (2011) used TIRI to visualize apple scab infections on apple seedling leaves prior to the development of visible lesions. TIRI can assess apple scab infections since infections disrupt the cuticle of apple leaves, which leads to heightened transpiration levels and abnormally low temperatures at infection sites (Oerke et al. 2011). The lower temperature at apple scab infection sites can, therefore, be distinguished from the rest of the leaf by TIRI using specific temperature thresholds (Oerke et al. 2011). qPCR also holds potential for quantification of $V$. inaequalis infections (Gusberti et al. 2012). Gusberti et al. (2012) developed a TaqMan probe-based quantitative assay that targets the ATP-binding cassette transporter 2 (ABC 2) of $V$. inaequalis. The qPCR assay revealed a good correlation between pathogen DNA quantities and visual ratings of apple scab lesions (Gusberti et al. 2012).

The main aim of the current study was to establish a laboratorybased biological efficacy benchmark model for apple scab infection and mancozeb deposition. A yellow fluorescent pigment was used as a tracer of mancozeb for obtaining benchmark values of deposition that can be used in apple orchards in precision management of foliar plant pathogens with contact fungicides. Since the quantification of $V$. inaequalis apple leaf infections is challenging, two methods were evaluated for quantification of the pathogen in apple seedling leaves including thermographic infrared image analyses and qPCR analysis.

\section{Materials and Methods}

Spray application and deposition analyses. Apple seedling production. Apple seedlings were produced from seeds of the apple scab susceptible cultivar 'Starking', as previously described (Rossouw et al. 2018). Seedlings were grown in seedling trays containing removable tray cells, which aided spray applications onto the seedlings (see below). Two weeks after planting, when the seed leaves emerged, a broad-spectrum water-soluble fertilizer (Multifeed classic, Nulandis, South Africa) was applied biweekly to seedling trays. Seedlings were grown at $23^{\circ} \mathrm{C}$ and a 12 -h light period until at least four fully expanded leaves emerged (approximately 8 weeks after planting).

Trial treatments. Seven treatments were evaluated and included: untreated-uninoculated control, $0 \times$ (water control) and mancozeb applied at $0.15 \times, 0.3 \times, 0.45 \times, 0.6 \times, 1.0 \times$ dosages. The $1.0 \times$ mancozeb treatment consisted of the recommended Dithane M-45 800 WP
NT (Dow AgroScience, Bryanston, South Africa) dosage of 1.5 $\mathrm{g} /$ liter. The $1.0 \times$ treatment spray solution also included $1 \mathrm{ml} / \mathrm{liter}$ of the SARDI (SARDI, Loxton, South Australia) 40\% EC yellow fluorescent pigment. The mancozeb treatments also contained the yellow fluorescent pigment at the relevant concentrations; for example, the $0.3 \times$ treatment contained $0.3 \mathrm{ml} /$ liter of the SARDI pigment. Each treatment was replicated 14 times, with a replicate consisting of one seedling. Four of the replicates were used for spray deposition analysis, whereas the remaining 10 replicates were used for inoculation with $V$. inaequalis. The experiment was conducted four times.

To simulate spray applications in apple orchards, apple seedlings were sprayed with mancozeb and control water solutions using an electronic knapsack spray machine (Rovic leers electric knapsack, Blackheath, Cape Town, South Africa). The spray machine was fitted with a single brown - Albuz ATR 80 nozzle (Solcera, Evreux cedex, France), which was set to deliver 0.4 liter/min. The nozzle containing sprayer arm was attached to a mechanically actuated arm that moved once over a seedling in a radial pattern at a constant speed of $0.75 \mathrm{~m} / \mathrm{s}(2.7 \mathrm{~km} / \mathrm{h})$ (Fig. 1A). One seedling was placed per spray application under the spray nozzle at a distance of $40 \mathrm{~cm}$ (Fig. 1B).

Spray treatments were applied to each seedling at a volume of $\pm 0.5 \mathrm{ml}$ spray solution per seedling. Thorough mixing of the yellow fluorescent pigment and mancozeb suspensions were conducted periodically throughout spray applications. The sprayer reservoir and spray nozzle were thoroughly rinsed with water after each treatment. Seedlings were dried for $24 \mathrm{~h}$ at room temperature $\left( \pm 23^{\circ} \mathrm{C}\right)$, after which inoculation and deposition assessments were made.

Only 5-day-old seedling leaves were used for deposition quantity and pathogen infection assessments. These leaves were identified by first marking the youngest leaf on each seedling with a small rubber band 5 days before the start of each trial. Over the 5 days leading to treatment application, new leaves unfolded on each seedling. On the day of the trial, the rubber band was moved to the new fully unfolded leaf, ensuring that each seedling had at least one leaf younger than 5 days.

Deposition analysis. Experimental leaves of each seedling were removed from seedlings and transported to a dark room. Spray deposition quantity on leaves was determined using a spray deposition analysis protocol described by van Zyl et al. (2013), with the exception that a different camera was used. Digital photos were taken with a Canon EOS 5-DSR camera equipped with a 100-mm EFS macro lens in Canon RAW file format (CR2 28 MB). Digital image analysis was conducted using Image Pro Plus software (version 7.0, Media Cybernetics, www.mediacy.com) as described by van Zyl et al. (2013, 2014). RAW images were converted to 8-bit Exif-TIFF format (.TIF $\sim 30 \mathrm{MB}$ ) with Digital Photo Professional version 4.0.0.0 (CANON INC., Centurion, South Africa). Deposition quantity was measured as the percent leaf area covered with yellow fluorescent particles (FPC\%, fluorescent particle coverage).

The yellow fluorescent pigment deposition quantity (FPC\%) achieved in each treatment was converted to mancozeb residues, which will hereafter be referred to as derived mancozeb residues. The derived mancozeb residues were obtained using a correlation equation $\left(\mathrm{R}^{2} 0.861\right)$ that was previously established between mancozeb residues and FPC\% on apple seedling leaves (Rossouw et al. 2018). The equation was: Average derived mancozeb residue $(\mathrm{mg} / \mathrm{kg})=$ $212.920 \times$ average $\mathrm{FPC} \%$.

$V$. inaequalis inoculum production. $V$. inaequalis conidial inoculum was produced using a cellophane agar plate technique as described by Parker et al. (1995), with a few slight modifications. Three single-spore $V$. inaequalis isolates (CGL, KCL, and Bub-16) obtained from scab lesions in the Koue Bokkeveld area (Western Cape, South Africa) were each grown on potato dextrose agar (PDA; MERCK Biolab, Gauteng, South Africa) at $18^{\circ} \mathrm{C}$ until the fungal colony reached a diameter of $2 \mathrm{~cm}$. A new $90 \mathrm{~mm}$ PDA plate was inoculated for each of the isolates using colonized agar disks $(0.5 \mathrm{~cm}$ diameter) from the edge of the colonies, five plugs per plate. Plates were incubated at $18^{\circ} \mathrm{C}$ and continuous light for 5 to 6 weeks until colonies reached a diameter of approximately $2 \mathrm{~cm}$. Mycelia 
suspensions were made by combining $20 \mathrm{ml}$ of distilled water with five colonies that were macerated with a scalpel. Two milliliters of the mycelial suspension was transferred to a cellophane membrane covered PDA plate, which was incubated under constant light conditions at $18^{\circ} \mathrm{C}$ for 7 days. Longer incubation times resulted in a reduction in the number and viability of conidia (Rossouw 2016). Conidia were harvested from plates using $15 \mathrm{ml}$ of sterile distilled water per plate. Suspensions were strained through a double layer of sterilized Mira cloth (Merck KGaA, Darmstadt, Germany) and centrifuged at $2,000 \mathrm{rpm}$ for $5 \mathrm{~min}$. The supernatant was poured off, and the conidia were resuspended in $2 \mathrm{ml}$ sterile distilled water. Spore suspensions were adjusted to a final concentration of $2 \times 10^{5}$ conidia/ml using a hemocytometer, and the conidial suspensions of each of the three isolates were combined. Viability of conidia was determined for each

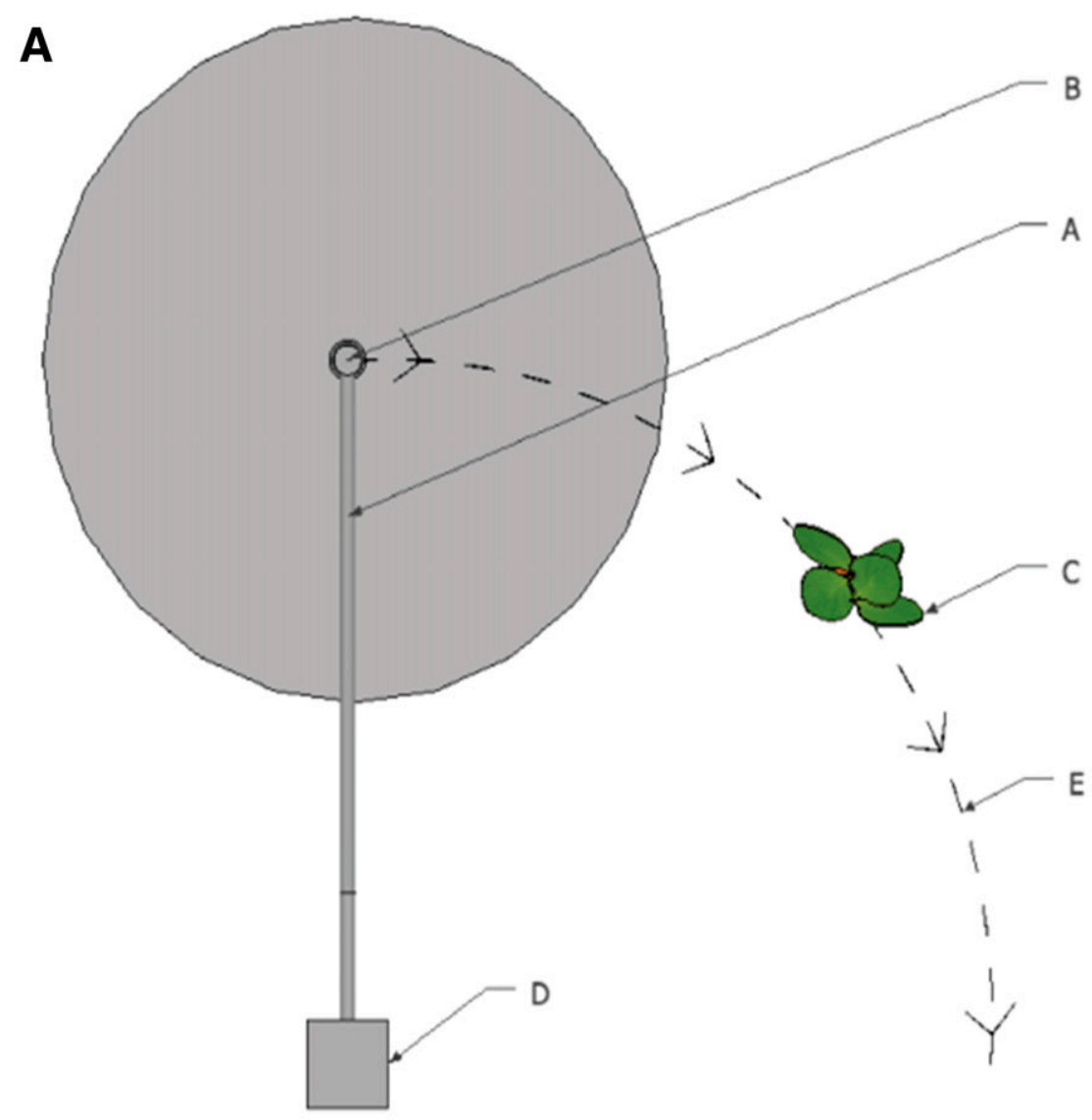

B

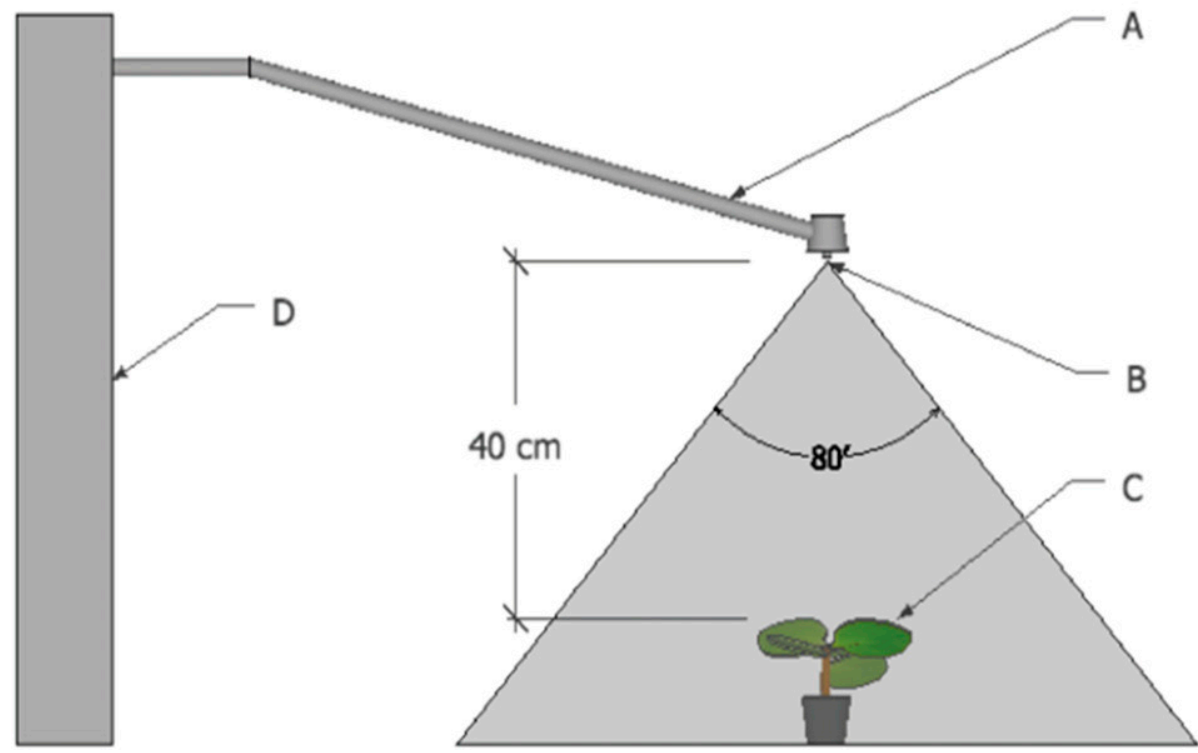

Fig. 1. Visual representation of a mechanically actuated spray arm from (A) above and (B) the side, which was used to apply various mancozeb and yellow fluorescent pigment spray treatments to apple seedlings. The figures show the orientation and proximity of the spray nozzle to the apple seedlings: A, spray arm attached to mechanical actuator, B, Albuz ATR 80 brown hollow cone nozzle, C, single apple seedling, D, mechanical actuator, and E, spray path of spray swath. 
trial by spraying $200 \mu \mathrm{l}$ of the spore suspension onto a water agar (WA) plate $(90 \mathrm{~mm}$ diameter) that was incubated at room temperature $\left( \pm 23^{\circ} \mathrm{C}\right)$ for $24 \mathrm{~h}$. One hundred conidiospores were counted under a light microscope to determine the percentage of germinated (viable) conidiospores.

Inoculation of apple seedlings with $\boldsymbol{V}$. inaequalis. Seedlings were inoculated with $V$. inaequalis $24 \mathrm{~h}$ after applying mancozeb sprays, by spray inoculating each seedling with $0.4 \mathrm{ml}$ of a $2 \times 10^{5}$ conidia/ml suspension using a hand held spray bottle. Each spray ejection from the bottle produced $\pm 0.1 \mathrm{ml}$, and each seeding thus received four sprays. The applied spray volume did not cause excessive moisture or run-off. The inoculated seedlings were placed in completely randomized block design in a Perspex humidity chamber $(530 \times 310 \times 500 \mathrm{~mm}), 28$ seedlings per chamber. Care was taken to prevent the leaves of the seedlings from touching, by spacing seedlings within the chamber so that the leaves from adjacent seedlings were not in contact with each other. The Perspex humidity chamber consisted of a Perspex box containing one wire rack and two vent holes on each side of the chamber. Humidity in the chamber was maintained by lining the back of the humidity chamber with a water-soaked filter paper of which the tip was submerged into a metal pan with water at the bottom of the Perspex box. The Perspex humidity chambers with both vents closed, yielding a relative humidity $(\mathrm{RH})$ of approximately 95 to $100 \%$, were incubated at $18^{\circ} \mathrm{C}$ for $48 \mathrm{~h}$ without light, for the initial infection period. Following the initial infection period, the RH was reduced to 75 to $85 \%$ by opening one of the vent holes on each side of the chamber. Incubation was continued for another 7 days with a light period of $12 \mathrm{~h}$ at $18^{\circ} \mathrm{C}$; total of 9 days postinoculation (DPI).

Disease quantification. Thermal infrared imaging. Thermographic disease quantification was done by TIRI based on work done by Oerke et al. (2011). Pilot trials showed that 9 days postinoculation (dpi) was the optimal time for disease quantification. At an earlier time point (6 days), the inoculated untreated control leaves' infection sites did not produce distinct enough areas with a lower temperature, which is indicative of $V$. inaequalis infection based on TIRI analysis. Assessments made at a later time point (13 days) could not be analyzed with TIRI since infection sites in the inoculated untreated control seedling leaves were too advanced, and no differences in temperature could be discerned across the leaf surface. Therefore, all assessments were made at 9 days postinoculation.

The inoculated apple seedlings were removed from the humidity chamber and left for $20 \mathrm{~min}$ on a laboratory bench to equilibrate to the outside environment $\left(20 \pm 3^{\circ} \mathrm{C}, 45\right.$ to $\left.55 \% \mathrm{RH}\right)$. A single excised seedling leaf was placed on a foam stand $(15 \mathrm{~mm}$ (height) $\times 3 \mathrm{~mm} \times$ $3 \mathrm{~mm}$ ) mounted on a heat pad, which was set at $28^{\circ} \mathrm{C}$, in order to create a strong thermal contrast between the leaf and the background. Care was taken to minimize the time from excising the leaves to capturing the thermogram.

A thermal infrared camera (Model A 615, FLIR Systems, Inc., Wilsonville, OR, U.S.A.) was used to capture still thermograms of leaves. The spectral resolution of the thermal camera was 7.5-14 $\mu \mathrm{m}$, with a thermal resolution of 0.05 Kelvin $(50 \mathrm{mK})$ and absolute thermal accuracy of $\pm 2 \mathrm{~K}$. The camera was equipped with a $25^{\circ} \times 19^{\circ}$ (IR resolution of $640 \times 480$ pixels) field of view lens and spatial resolution of $0.68 \mathrm{MRAD}$. The minimum focal range of the lens was $0.25 \mathrm{~m}$.

The thermal camera was mounted on a monopod, with the camera lens directed downward $\left(90^{\circ}\right.$ from a horizontal position), at a distance of $0.3 \mathrm{~m}$ from the leaf (Fig. 2). The camera was controlled with the FLIR Tools (FLIR Systems, Inc.) freeware to capture still thermographs of leaves. Reflectance temperature, atmospheric temperature, and humidity of the camera was calibrated before each of the four trials. After thermograms were captured, the leaves were stored at $-85^{\circ} \mathrm{C}$ for qPCR analyses; 10 replicates per treatment were pooled to obtain a total of five replicates per treatment.

The captured thermal leaf images were processed to determine the area of leaves infected with $V$. inaequalis. This action was possible since the infection sites produced distinct areas with lower temperature (Fig. 3A). Image processing was done by using temperature values of pixels produced by the thermograms. Thermal thresholding was used to isolate the area on the leaves infected with $V$. inaequalis. The process started by converting leaf thermograms to a comma-separated value (CSV) file format with FLIR quick report version 1.2 Sp1 (FLIR Systems, Inc.). A thermal thresholding tool was implemented using a customized Matlab code (Matlab version 2017b, The MathWorks, Inc., Natick, MA, U.S.A.). A two-stage thresholding method was used. In the first stage, the leaf was isolated from the background; this was facilitated by using a heat pad that created a good thermal contrast between the leaf and the background. The temperature threshold for the first thresholding step was set at $24.5^{\circ} \mathrm{C}$. In the second thresholding step, infected leaf areas were isolated from the rest of the leaf. This step was done by manually inspecting each isolated leaf for unevenly distributed cooler spots on the leaf (Fig. 3C). If no uneven cooler areas were present, the leaf was considered to have no infection. If uneven cooler areas were identified on leaves, the second threshold was applied to determine the area infected (Fig. 3C and D). The thermal threshold temperature for the second threshold was defined as $0.8^{\circ} \mathrm{C}$ above the minimum temperature of the specific leaf. The number of pixels in the isolated infected area was used to calculate the percent area infected on the total leaf area. The area infected of each treatment was subsequently expressed as the relative percentage of disease control when compared with the inoculated control treatment. The relative percent disease control obtained with the TIRI quantification method will hereafter

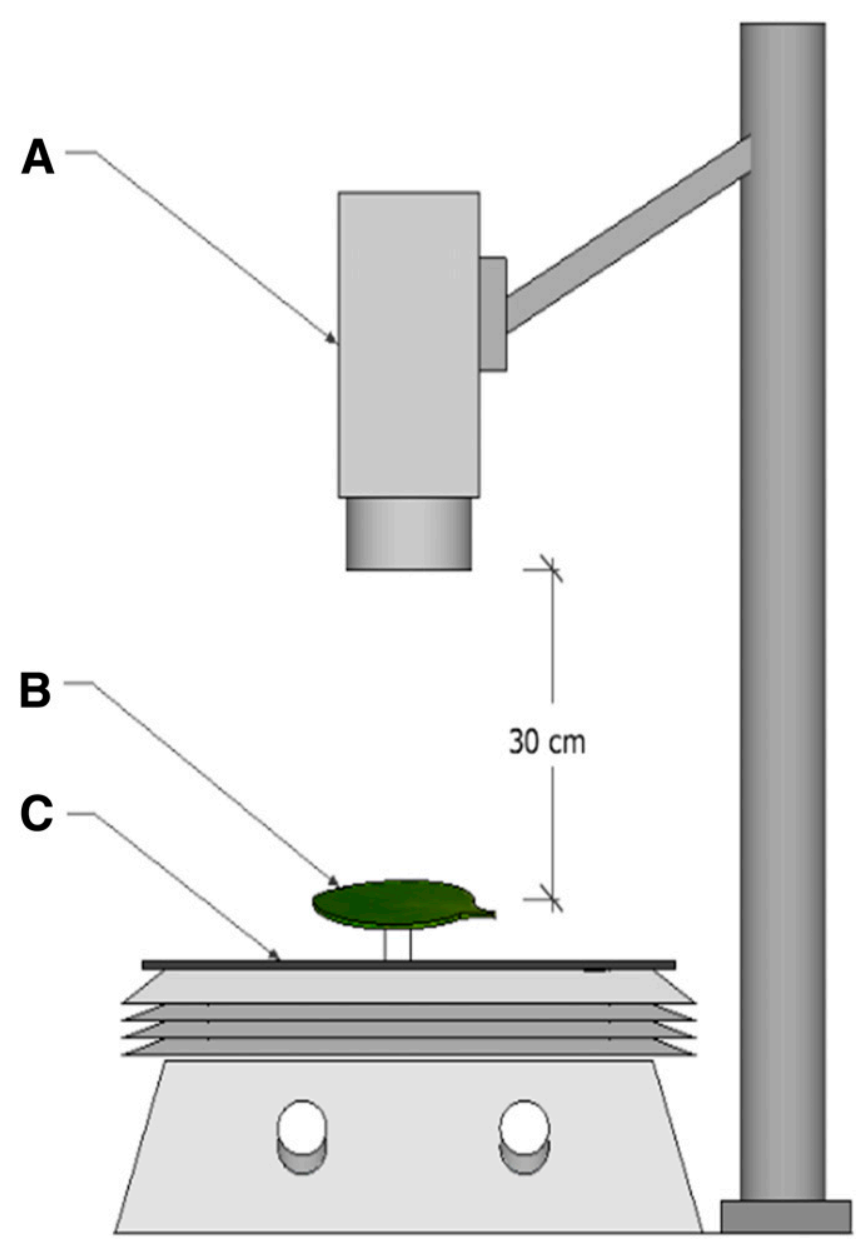

Fig. 2. Illustration of the thermal infrared imaging setup, camera, and heating pad used to conduct quantification of Venturia inaequalis infections on apple leaves through infrared thermal imaging analysis. The apple leaf was placed on a stand above a heat plate in order to create a strong background contrast with the target leaf, which facilitated thermal image analyses. The thermal camera was mounted $30 \mathrm{~cm}$ directly above the leaf position: A, Flir A 615 thermal camera, B, target apple leaf, and $\mathrm{C}$, heat pad set to $28^{\circ} \mathrm{C}$. 
be referred to as the percentage $V$. inaequalis thermal control (\%VIthermal control) that was determined with the following equation:

$$
\begin{aligned}
& \% V I-\text { thermal control }=100 \\
& -\left[\left(\frac{\% \text { area infected treatment } \alpha}{\% \text { area infected inoculated control }}\right) \times 100\right]
\end{aligned}
$$

where "\% area infected treatment $\alpha$ " is the $\%$ leaf area infected by $V$. inaequalis determined for each treatment and "\% area infected inoculated control" is the \%leaf area infected by $V$. inaequalis in the inoculated control treatment.

qPCR quantification. Apple seedling leaves from the thermography experiments that were stored at $-85^{\circ} \mathrm{C}$ in $15-\mathrm{ml}$ tubes were lyophilized for $24 \mathrm{~h}$. The lyophilized leaves were manually ground to a fine powder in the $15-\mathrm{ml}$ tubes with a sterile stainless-steel scalpel. Fifty milligrams of the powdered leaves were transferred to 2-ml centrifuge tubes containing $0.5 \mathrm{~g}$ glass beads $(2 \mathrm{~mm})$, and leaves were ground further by shaking in a Retch MM400 mixer mill (GmbH and Co., Haan, Germany) at $30 \mathrm{~Hz}$ for $5 \mathrm{~min}$. V. inaequalis DNA was extracted from powdered apple leaf tissues using a NucleoSpin plant II DNA extraction kit (Macherey-Nagel GmbH and Co., Düren, Germany) according to the manufacturer's instructions, with minor modifications. Firstly, an internal control gene DNA fragment was added to the PL1 extraction buffer to a final concentration of $1 \times$ $10^{9}$ copies $/ \mu 1$. The internal control gene fragment consisted of a linearized plasmid containing a mutated $E$. coli gene (Daniell et al. 2012). The plasmid was extracted from E. coli cells and linearized as described by Moein et al. (2019). Other modifications that were made to the manufacturer's DNA extraction kit instructions included: (i) using $800 \mu \mathrm{l}$ of PL1 buffer instead of the prescribed $400 \mu \mathrm{l}$, (ii)
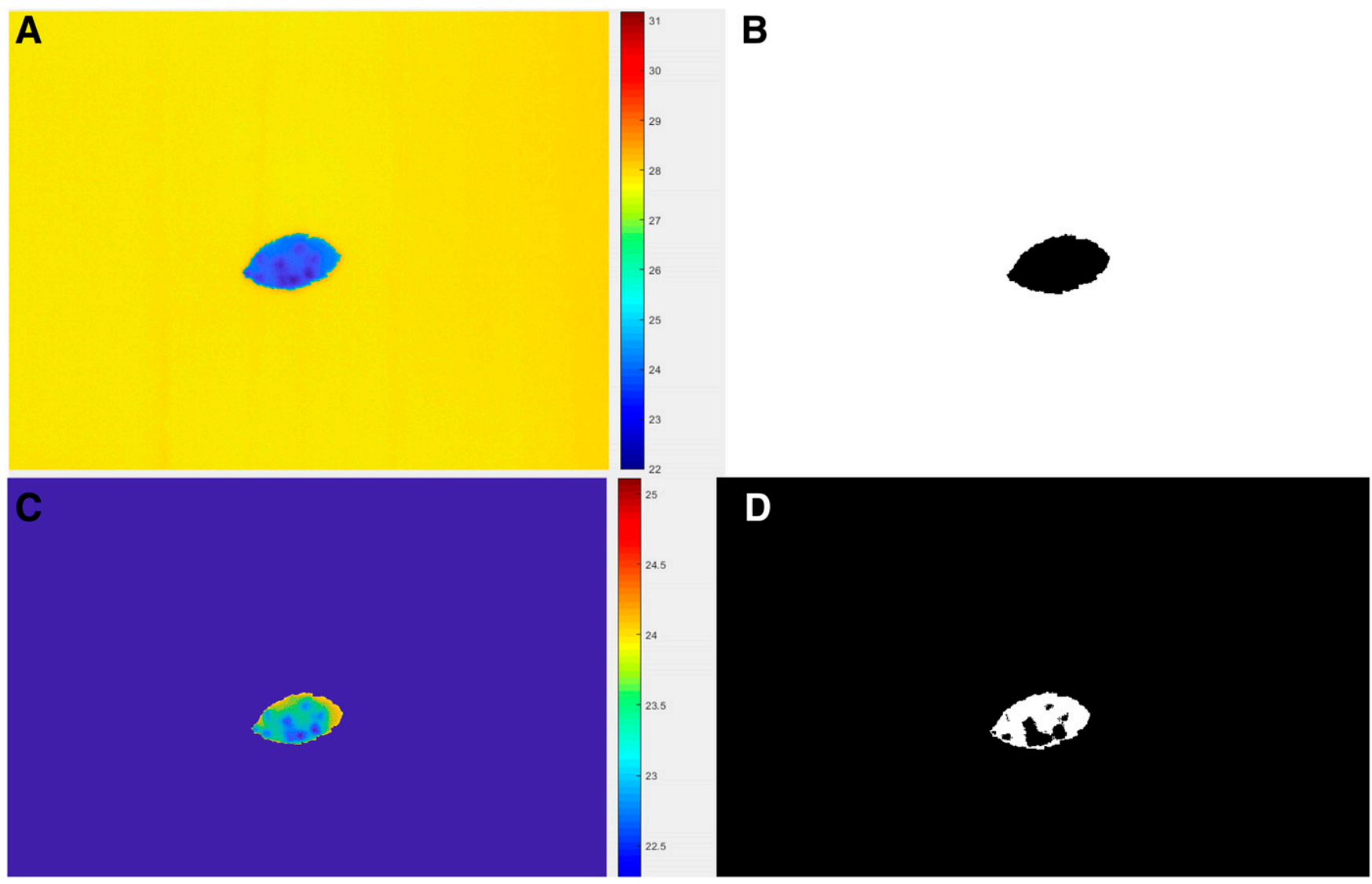

Fig. 3. Illustration of the two step process used for isolating apple leaf background from Venturia inaequalis infections sites during the thermographic infrared image analysis process: (A) apple leaf with apple scab infection before background was removed, (B) apple leaf isolated from background, (C) isolated leaf before infected area was isolated, and (D) apple leaf with infected area shaded black within the leaf area. 
was first determined by qPCR amplifying the internal control mutated $E$. coli gene in a subsample of leaf extracts. It was important to establish whether PCR inhibitors were present since mancozeb and the fluorescent pigment applied to leaves from which DNA was extracted could potentially have caused qPCR inhibition. A mutated E. coli gene standard curve was made using the linearized plasmid containing the internal control gene at 10 to $10^{9}$ copies per reaction in tenfold dilutions. qPCR reaction and amplification conditions were conducted as described by Moein et al. (2019). qPCR amplification using the undiluted leaf DNA samples at a volume of $1 \mu \mathrm{l}$ in the $20 \mu \mathrm{l}$ qPCR reactions caused inhibition, but not when $2 \mu \mathrm{l}$ of a five-times diluted leaf DNA extract (1 part pathogen DNA and 4 parts elution buffer) was used. The latter was evident from the fact that qPCR amplification of DNA extracted from the untreateduninoculated control yielded similar internal control gene quantities to those from DNA extracted from the highest mancozeb concentration treatment $(1.0 \times$ treatment $)$.

Leaf DNA samples from all seven treatments, five replicates per treatment, from each of the four trials were subjected to qPCR analysis using the $\mathrm{ABC} 2 \mathrm{qPCR}$ assay. qPCR reaction and amplification conditions were as described for the $\mathrm{ABC} 2$ standard curve using $2 \mu \mathrm{l}$ of a five-times diluted leaf DNA extract in each $20 \mu \mathrm{l}$ qPCR reaction. In each qPCR run, two replicates of one of the standard curve concentrations were included, which allowed quantification through the importation of the standard curve. Each leaf DNA sample was analyzed in duplicate.

Percent disease control was expressed as the relative percent increase in disease control when compared with the inoculated untreated control treatment. The percent disease control assessed using qPCR quantification will hereafter be referred to as percentage $V$. inaequalis DNA control (\%VI-DNA control).

$\%$ VI - DNA control $=100$

$$
-\left[\left(\frac{\text { Copies per reaction } \alpha}{\text { Copies per reaction control }}\right) \times 100\right]
$$

In the equation, "copies per reaction $\alpha$ " is the calculated copies of $V$. inaequalis DNA determined for each treatment and "calculated copies per reaction control" is the calculated copies of $V$. inaequalis DNA in the inoculated untreated control treatment.

Statistical analyses. Deposition quantity (FPC\%), percentage disease control with thermal imaging analyses and percentage disease control with qPCR quantification were subjected to analyses of variance (ANOVA). The percentage data sets were not normally distributed, and using multiple transformation procedures were unsuccessful at obtaining normality, which is a requirement for ANOVA. However, Blanca et al. (2017) recently reported the robustness of the $F$ test for variance under many different situations including data sets that deviated from normality, which thus allows for ANOVA to be used on these data sets. Tukey's honestly significant difference (HSD) test was used to identify differences between treatments at 95\% confidence. Pearson's correlation test was used to demonstrate the correlation between mancozeb residue and deposition quantities. All statistical analyses were done using XLSTAT (version 2011.02.06, Addisoft, New York, U.S.A.).

\section{Results}

Spray application and deposition analyses. Mancozeb and yellow fluorescent spray applications yielded evenly distributed distinct droplets over the seedling leaf surface when leaves were visualized using photo-macrophotography under UV light. An increase in the applied concentration of fluorescent pigment was clearly visible (Fig. 4).

ANOVA of deposition quantity indicated a significant treatment $x$ trial $(P<0.0001)$ interaction. Although the interaction was significant, the data of the four trials were combined. This was due to the fact that the cause of the interaction was limited to the (i) $1 \times$ concentration of trial 1 that was significantly higher than the $1 \times$ concentration of trial 2 and (ii) the $0.45 \times$ concentration of trial 2 that was significantly higher than the $0.45 \times$ of trial 1 and 3 (Supplementary Table S1). Considering the combined trial data, there was a significant treatment effect $(P<0.0001)$. The $1 \times$ concentration yielded a significantly higher deposition quantity $(4.16 \mathrm{FPC} \%)$ than the $0.6 \times$ concentration (2.74 FPC\%) (Table 1). Both of these treatments yielded significantly higher deposition quantity than the remaining mancozeb treatments and control. Deposition quantity of the $0.15 x$ concentration $(0.63 \mathrm{FPC} \%$ ) was very low and did not differ significantly from the water control (Table 1). Spray deposition quantity (FPC\%) increased linearly as mancozeb and fluorescent pigment concentration (treatment effect) increased $\left(\mathrm{R}^{2}=0.91\right)$.

ANOVA of derived mancozeb residues showed significant differences among treatments $(P<0.0001)$. All treatments were significantly different from each other except for the $0.15 x$ and $0.30 \times$ treatments (132.94 to $243.98 \mathrm{mg} / \mathrm{kg}_{\text {DW }}$ ) (Table 1$)$.

Inoculum production and inoculation of apple seedlings with $V$. inaequalis. Germination percentages of conidiospore suspensions ranged between 80 and $85 \%$ for each of the four trials. The high viability of the inoculum combined with highly conducive postinoculation incubation conditions resulted in rapid symptom development. Nine days postinoculation, when disease rating with TIRI and qPCR analysis were conducted, the inoculated control $(0 \times$ treatment $)$ treatment seedlings showed light brown diffuse apple scab lesions. No visible lesions were observed for any of the other treatments $(0.15-$ $1 \times$ treatments).

Disease quantification. Thermal infrared imaging. ANOVA of $\%$ VI-thermal control showed that there was no significant trial $\times$ treatment $(P=0.715)$ interaction. There was a significant difference between treatments $(P<0.0001)$. The \%VI-thermal control increased significantly from $0 \%$ for the control treatment to $63.86 \%$ for the $0.15 \times$ treatment. The $0.15 \times$ treatment had a significantly lower $\%$ VI-thermal control (63.86) than the rest of the mancozeb treatments, which did not differ from each other (Table 2).

qPCR analyses. The ABC 2 qPCR assay successfully amplified $V$. inaequalis DNA from all of the inoculated treatments. ANOVA of $\%$ VI-DNA control indicated no significant trial $\times$ treatment $(P=$ $0.595)$ interaction, but did indicate a significant effect of treatment $(P<0.0001)$. For the effect of treatment, the same trend was observed as for the \%VI-thermal control data set. However, there were more mancozeb treatments that differed from each other for the \% VIDNA data. A very sudden and significant increase in \%VI-DNA control was evident at the $0.15 \times$ treatment $(98.18 \%)$ in comparison with the water control (Table 2). The highest \%VI-DNA control was observed at the $1 \times$ and $0.60 \times$ treatments, which were significantly higher than the other mancozeb treatments (Table 2). A good and significant $(P<0.0001)$ Pearson correlation was observed between the $\%$ VI-DNA control and \%VI-thermal control data sets $(\mathrm{r}=0.858)$.

Benchmark modeling. Various models were fitted to the data, to model the reaction of percentage disease control to deposition quantity (FPC\%). For the qPCR quantification method and the TIRI quantification method, the 'Von Bertalanffy growth equation' fitted the data the best. For the qPCR quantification method, the function that fitted the data best was: \%VI-DNA control $=99.614 *[1-$ $\operatorname{Exp}(-6.925 * \mathrm{FPC} \%)]\left(\mathrm{R}^{2}=0.999\right)$ (Fig. 5A). There was an excellent correlation $(\mathrm{r}=0.999)$ between observed values and predicted values $(P<0.0001)$. For the TIRI quantification method, the function that fitted the data best was: \%VI-thermal control $=98.678 *[1-$ $\operatorname{Exp}(-1.809 * \mathrm{FPC} \%)]\left(\mathrm{R}^{2}=0.963\right)$ (Fig. 5B). An excellent correlation $(r=0.954)$ also existed for the TIRI quantification method between the observed percentage disease control and predicted percentage disease control values $(P<0.0001)$.

The model for each quantification method was used to predict deposition quantity (FPC\%) levels at which $50 \%\left(\mathrm{FPC}_{50}\right), 75 \%$ $\left(\mathrm{FPC}_{75}\right)$, and $90 \%$ ( $\left.\mathrm{FPC}_{90}\right)$ disease control benchmarks would be realized. For the VI\%-qPCR control, the $\mathrm{FPC}_{50}, \mathrm{FPC}_{75}$, and $\mathrm{FPC}_{90}$ benchmarks were predicted as being $0.101 \mathrm{FPC} \%, 0.20 \mathrm{FPC} \%$, and 0.34 FPC\%, respectively. For the VI\%-thermal control the predicted $\mathrm{FPC}_{50}, \mathrm{FPC}_{75}$, and $\mathrm{FPC}_{90}$ benchmarks were higher than for the qPCR method, being $0.40 \mathrm{FPC} \%, 0.79 \mathrm{FPC} \%$, and $1.35 \mathrm{FPC} \%$, respectively. 


\section{Discussion}

The current study developed spray deposition benchmarks $\left(\mathrm{FPC}_{50}\right.$, $\mathrm{FPC}_{75}$, and $\mathrm{FPC}_{90}$ ) for apple orchard trees using a mancozeb-apple scab model. Two different sets of benchmarks were obtained when disease severity was quantified using a qPCR and TIRI approach. The benchmark model created with the TIRI assessment method yielded $\mathrm{FPC}_{50}, \mathrm{FPC}_{75}$, and $\mathrm{FPC}_{90}$ values that were higher $(0.40 \%$, $0.79 \%$, and $1.35 \mathrm{FPC} \%$, respectively) than those estimated using the qPCR quantification data $(0.10,0.20$, and $0.34 \mathrm{FPC} \%$, respectively). This was due to the relatively lower levels of disease control (63.86-84.15\%) obtained with the TIRI disease assessment method than for qPCR quantification (98.18-99.5\%) at the two lowest mancozeb dosages $(0.15$ and $0.3 \times)$. Considering that no visible lesions developed at the two lowest mancozeb dosages, whereas lesions did develop on the untreated control leaves, qPCR quantification was more accurate for assessing disease control, although it slightly underestimated disease control. TIRI resulted in a relatively large underestimation of disease control. This is not unexpected since TIRI likely not only assesses pathogen quantity, as is the case for qPCR, but it measures the host response in cells surrounding infected cells. The growth of hyphae in infected host plant cells probably also affects (water status of leaf tissue) host cells surrounding the infected
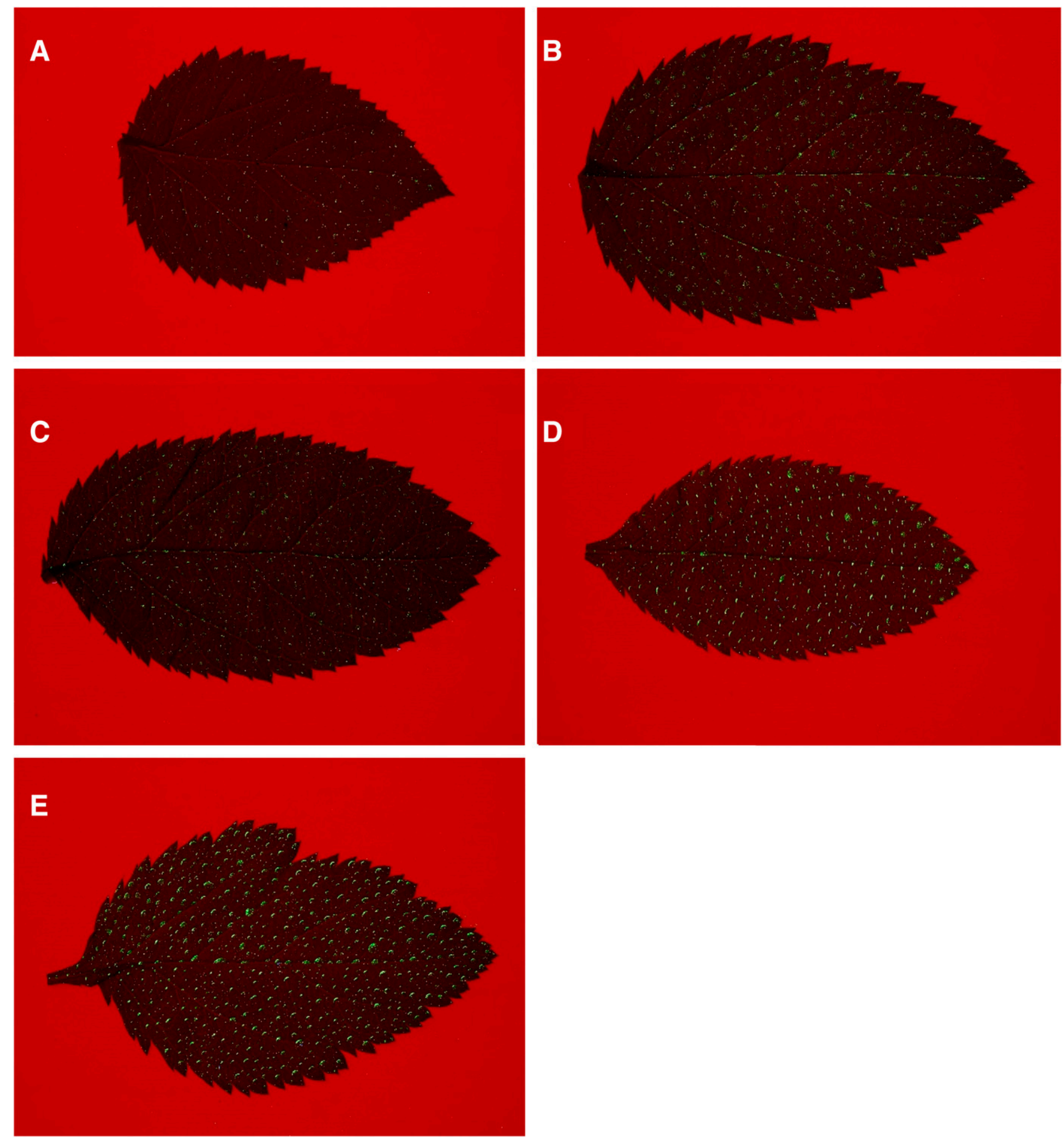

Fig. 4. Digital images of the upper surface of apple seedling leaves sprayed with increasing concentrations of mancozeb together with a yellow fluorescent pigment illuminated by ultraviolet light. Concentrations increased from $0.15 \times(\mathrm{A})$ to $1.0 \times(\mathrm{E})$ the recommended dose of mancozeb $(1.5 \mathrm{~g} /$ liter) and fluorescent pigment of $1 \mathrm{ml} /$ iter. The deposition quantity achieved increased visually as the concentration of mancozeb and yellow fluorescent pigment increased. Digital images of the full concentration range are shown as (A) $0.15 \times$, (B) $0.30 \times,(C) 0.45 \times,(D) 0.60 x$, and (E) $1 \times$. 
cell tissue (Oerke et al. 2011). The leaf water content in cells below the infection sites, as well as the infected cells, increases, resulting in increased transpiration that ultimately leads to lower leaf temperatures (Oerke et al. 2011), which is quantified by TIRI. Subcuticular growth of $V$. inaequalis can locally increase the rate of transpiration on apple leaves at a very early stage of plant penetration, even before cuticular damage has occurred (Oerke et al. 2011). Therefore, at the two lowest mancozeb concentrations, TIRI probably measured the host's response to infections that were initiated but that were subsequently stopped and did not develop into lesions.

The postinfection activity of mancozeb at low dosages is unexpected, as suggested by our TIRI data for the two lowest mancozeb concentrations since mancozeb is known as a contact fungicide of which the breakdown products have a direct effect on fungal pathogens by inhibiting spore germination (Gullino et al. 2010). However, it is not inconceivable that mancozeb can have a postgermination activity since mancozeb has been reported to have moderate to high antisporulant activity when applied postinfection and postsymptom

Table 1. Spray deposition quantity (\%FPC) and derived mancozeb residues $\left(\mathrm{mg} / \mathrm{kg}_{\mathrm{DW}}\right)$ on apple seedling leaves sprayed with different concentrations of mancozeb and a fluorescent pigment

\begin{tabular}{llc}
\hline & \multicolumn{2}{c}{ Deposition $^{\mathbf{y}}$} \\
\cline { 2 - 3 } Treatment $^{\mathbf{x}}$ & FPC\% & $\begin{array}{c}\text { Derived mancozeb } \\
\text { residue }(\mathbf{m g} / \mathbf{k g} \mathbf{D w})^{\mathbf{z}}\end{array}$ \\
\hline $1 \times$ & $4.16 \mathrm{a}$ & $885.74 \mathrm{a}$ \\
$0.60 \times$ & $2.74 \mathrm{~b}$ & $583.41 \mathrm{~b}$ \\
$0.45 \times$ & $1.71 \mathrm{c}$ & $364.09 \mathrm{c}$ \\
$0.30 \times$ & $1.10 \mathrm{~cd}$ & $234.21 \mathrm{~d}$ \\
$0.15 \times$ & $0.63 \mathrm{de}$ & $134.14 \mathrm{~d}$ \\
$0 \times$ & $0.0 \mathrm{e}$ & $0 \mathrm{e}$ \\
\hline
\end{tabular}

$\mathrm{x}$ Treatments consisted of mancozeb applied at reduced dosages of the registered label concentration $(1 \times=1.5 \mathrm{~g} /$ liter $)$. A fluorescent pigment $(1 \mathrm{ml} /$ liter $)$ was added to the mancozeb solutions, which was used to determine deposition values.

${ }^{y}$ Means are the average of four trials, five replicates per trial. Values in each column followed by the same letter do not differ significantly $(P>0.05)$ according to Tukey's honest significance difference (HSD) test with a critical value of 4.494 for deposition quantity, quality and derived mancozeb residues.

$\mathrm{z}$ The derived mancozeb residue levels were determined using a correlation curve between mancozeb residue and FPC\% that was developed by Rossouw et al. (2018). The derive mancozeb residue ( $\left.\mathrm{mg} / \mathrm{kg}_{\text {dry weight }[\mathrm{DW}]}\right)$ values were calculated using the equation obtained from the correlation curve: Derived mancozeb residue $\left(\mathrm{mg} / \mathrm{kg}_{\mathrm{DW}}\right)=212.920 *$ average of FPC $\%$. development (Underdown et al. 2008; Wong and Wilcox 2001). The fact that infection was detected by TIRI at the two lowest mancozeb dosages, yet no lesion developed, is likely due to the delayed efficacy of mancozeb at these low dosages. Consequently, spores were able to germinate and initiate subcuticular infections, but these were stopped when mancozeb eventually killed the spores. The presence of a small amount of pathogen DNA detected using qPCR at the two lowest mancozeb dosages (98-99.5\% control) also supports the presence of a small quantity of pathogen, which was most likely derived from nonviable germinated spores that caused the failed infections detected by TIRI.

Since the TIRI benchmark model overestimated disease development, the qPCR benchmark model is deemed to be a more realistic benchmark model. qPCR did also result in a slight overestimation of disease development since $98.18 \%$ disease control was obtained at the lowest mancozeb dosage, whereas no visible lesions developed at this treatment 9 days postinoculation. As mentioned above, this is likely due to the detection of DNA from nonviable germinated spores. It is feasible that the detected DNA could have been from successful infections that would have developed into lesions if the leaves were incubated for longer than 9 days. However, a previous study showed that the application of mancozeb dosages of $0.15 \times$ and $0.3 \times$ did not result in the development of visual lesions when seedlings were left for up to 4 weeks (Rossouw 2016). The $\mathrm{FPC}_{75}$ and $\mathrm{FPC}_{90}$ values obtained with the qPCR benchmark model is deemed a realistic model since although no visible lesions developed, the fact that pathogen spores were able to start germinating, does pose a risk for a high-risk destructive pathogen such as $V$. inaequalis. The benchmarks required for 75 to $90 \%$ disease control (FPC\% of $0.20 \%$ and $0.34 \%$ ) are achievable when compared with those obtained in a previous study where commercial spray applications were made in apple orchards in South Africa. The FPC\% obtained in apple orchards ranged from 0.7 to $2.0 \mathrm{FPC} \%$ for 4-m-row-width orchards, and from 1.5 to $4.7 \mathrm{FPC} \%$ for $3.5-\mathrm{m}$-row-width orchards when sprays were applied using the standard South African industry tree-row-volume dosing model (Rebel 2019).

The only other tree crop for which benchmarks have been determined is citrus, where copper oxychloride and Alternaria brown spot were used as the model system (van Zyl et al. 2013). The $\mathrm{FPC}_{50}$ and $\mathrm{FPC}_{75}$ benchmarks on citrus were estimated at $2.07 \mathrm{FPC} \%$ and 4.14 FPC\%, respectively, which is higher than those established in the current study for apple using the apple scab-mancozeb model $(0.10 \%, 0.20 \%)$. It is thus evident that apple scab disease control using mancozeb can be achieved at lower deposition values compared with Alternaria brown spot control on citrus using copper oxychloride. Variation in benchmarks can be ascribed to differences in the

Table 2. Mean actual and predicted Venturia inaequalis percentage-control (VI\%-control) determined for apple seedling leaves sprayed with a concentration range of mancozeb and fluorescent pigment

\begin{tabular}{|c|c|c|c|c|}
\hline \multirow[b]{2}{*}{ Treatment $^{w}$} & \multicolumn{4}{|c|}{ VI\% -control $^{\mathrm{x}}$} \\
\hline & $\begin{array}{l}\text { VI\%-qPCR } \\
\text { controly }\end{array}$ & $\begin{array}{c}\text { Predicted } \\
\text { VI\% } \% \text {-qPCR control }{ }^{\mathrm{z}}\end{array}$ & $\begin{array}{l}\text { VI\%-thermal } \\
\text { controly }\end{array}$ & $\begin{array}{c}\text { Predicted } \\
\text { VI\% } \\
\text {-thermal control }\end{array}$ \\
\hline $1 \times$ & $99.79 \mathrm{a}$ & $99.61 \mathrm{a}$ & $99.97 \mathrm{a}$ & $98.63 \mathrm{a}$ \\
\hline $0.60 \times$ & $99.68 \mathrm{a}$ & $99.61 \mathrm{a}$ & $99.72 \mathrm{a}$ & $97.98 \mathrm{ab}$ \\
\hline $0.45 x$ & $99.54 \mathrm{~b}$ & $99.61 \mathrm{a}$ & $92.11 \mathrm{a}$ & $94.20 \mathrm{~b}$ \\
\hline $0.30 x$ & $99.50 \mathrm{~b}$ & $99.56 \mathrm{a}$ & $84.15 \mathrm{a}$ & $85.19 \mathrm{c}$ \\
\hline $0.15 x$ & $98.18 \mathrm{~b}$ & $98.34 \mathrm{~b}$ & $63.86 \mathrm{~b}$ & $67.11 \mathrm{~d}$ \\
\hline $0 \times$ & $0 \mathrm{c}$ & $0 \mathrm{c}$ & $0 \mathrm{c}$ & $0 \mathrm{e}$ \\
\hline
\end{tabular}

${ }^{w}$ Treatments consisted of mancozeb applied at reduced dosages of the registered label concentration $(1 \times=1.5 \mathrm{~g} /$ liter $)$. A fluorescent pigment $(1 \mathrm{ml} / \mathrm{liter})$ was added to the mancozeb solutions, which was used to determine the deposition values.

${ }^{x}$ Means are averages of four trials, five replicates per trial. Values in columns followed by the same letter do not differ significantly $(P>0.05)$ according to Tukey's honest significance difference (HSD) test with a critical value of 4.496 for VI\%-qPCR control and 4.496 for VI\%-thermal control.

y Apple seedlings were sprayed with mancozeb, inoculated with $V$. inaequalis and incubated for 9 days before disease assessments (qPCR and thermal) were conducted. The VI\%-qPCR control was determined using the V. inaequalis probe-based qPCR assay published by Gusberti et al. (2012), which targets the $\mathrm{ABC} 2$ gene sequence. The VI\%-thermal control was determined by a thermal infrared imaging assay based on the work done by Oerke et al. (2011).

$\mathrm{z}$ Mean predicted VI\%-control (thermal or qPCR) values were determined by subjecting FPC\% values of each treatment to the relevant equation obtained from VI $\%$ benchmark models (thermal or qPCR). Predicted VI\%-qPCR $=99.614 *[1-\operatorname{Exp}(-6.925 * \mathrm{FPC} \%)]$ and Predicted VI\%-thermal $=98.678 *[1-\operatorname{Exp}(-1.809 *$ $\mathrm{FPC} \%)]$ 
mode of action of fungicides (McCallan 1949; Usak 2015), model pathogen, leaf surface characteristics influencing droplet impaction, and fungicide persistence (Dorr et al. 2015). This suggests that it will be important to establish benchmark deposition values for specific crops, and possibly different contact fungicides. Internationally, cap$\tan$ and dithianon are the contact fungicides on which apple scab control is relied upon (Cuthbertson and Murchie 2003; Sutton et al. 2014). Future studies should investigate whether benchmark values for these fungicides will differ from those that are required for the control of apple scab using mancozeb.

The calculated benchmark values for the apple scab-mancozeb model is much lower than the registered mancozeb dosage (wettable powder mancozeb $750-800 \mathrm{~g} / \mathrm{kg}$ pure active used at $150 \mathrm{~g} / 100$ liter water) in South Africa. This dosage is also used in other countries such as Australia (Australian pesticide and veterinary medicines authority, 2018). The FPC $_{90}$ realized for mancozeb had FPC\% values that
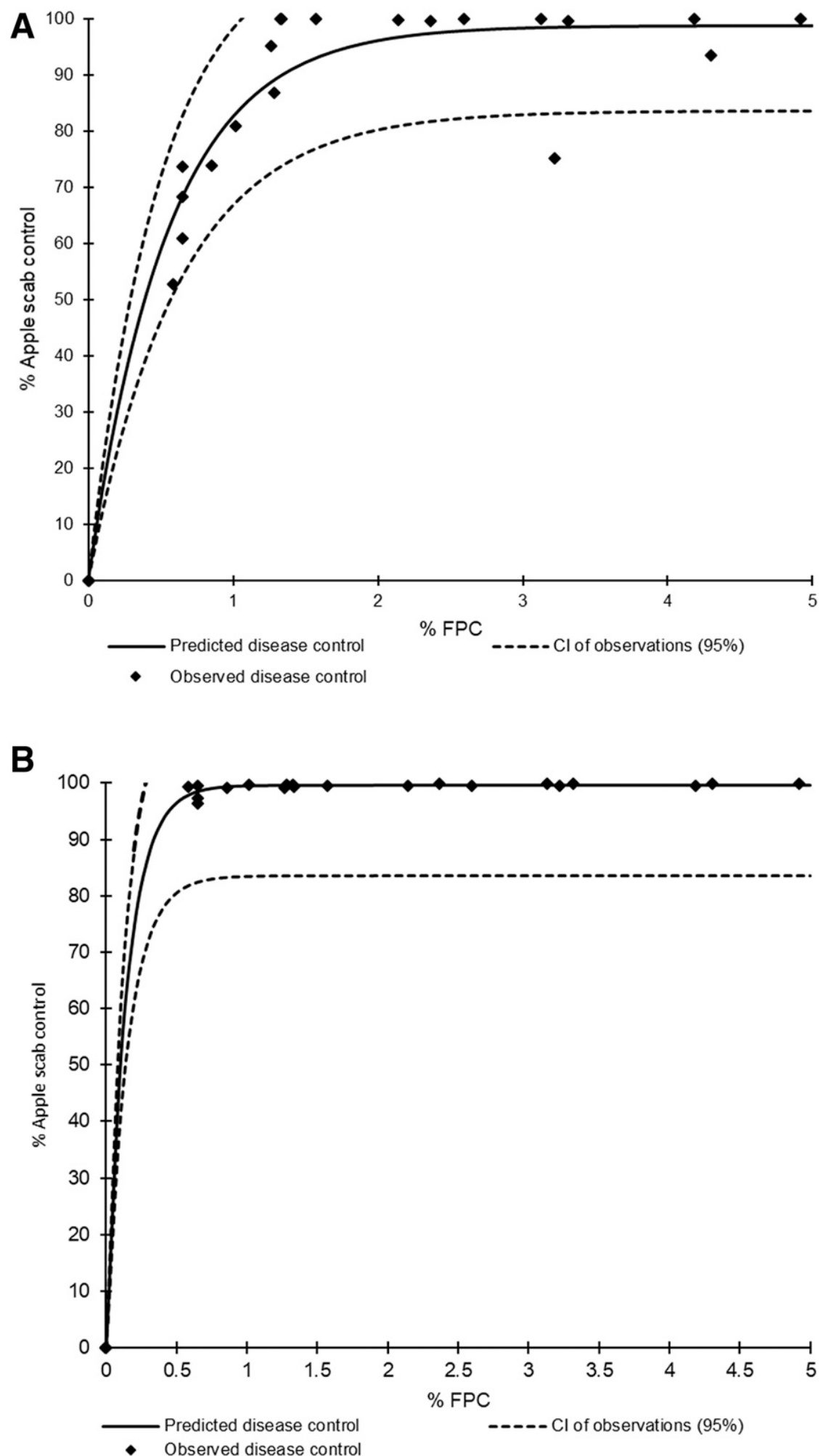

Fig. 5. Von Bertalanffy models predicting percentage apple scab control based on the deposition quantity of a yellow fluorescent pigment (FPC\%) and (A) qPCR quantification of Venturia inaequalis DNA where $V$. inaequalis percentage qPCR-control $=99.614^{*}\left[1-\operatorname{Exp}\left(-6.925^{*} \mathrm{FPC} \%\right)\right]$ and $(\mathrm{B})$ thermal infrared imaging where $V$. inaequalis percentage thermal-control $=98.678^{*}\left[1-\operatorname{Exp}\left(-1.809^{*} \mathrm{FPC} \%\right)\right]$. Each graph represents the values of four independent experiments, five replicates per experiment. 
corresponded to those obtained with the $0.15 \times$ mancozeb treatment, i.e., $85 \%$ lower than the registered mancozeb concentration. The high efficacy of mancozeb at low concentrations could be due to the residual effect of the soluble form of mancozeb (EBIS and EBI, ethylene bisisothiocyanate sulfide and ethylene bisisothiocyanate) being continuously released when exposed to water and UV radiation (Gullino et al. 2010). This effect could specifically be involved and be important for apple scab infections since $V$. inaequalis can only infect host tissue when free moisture is available (Bowen et al. 2011; MacHardy 1996c; Turner et al. 1986); each time free moisture is present on leaves more solubilization occurs. Since the current benchmarks were established without taking weathering into consideration, a higher deposition quantity will likely be required just following applications in order to take weathering due to rainfall, UV exposure, and leaf/fruit expansion into account. Low rainfall levels are likely to only have a marginal effect on mancozeb efficacy since Rossouw et al. (2018) reported an average loss of only $51.67 \%$ in FPC\% when 5 to $15 \mathrm{~mm}$ rain was applied under laboratory conditions. Therefore, mancozeb applied at $0.15 \times$ and $0.30 \times$ dosages, which yields FPC $\%$ values of approximately 0.63 and $1.10 \mathrm{FPC} \%$, theoretically will still provide near and above $90 \%$ disease control $(0.31 \mathrm{FPC} \%=87.97 \%$ disease control and 0.54 $\mathrm{FPC} \%=97.24 \%$ disease control, respectively) on leaves following rain events. The current study did not develop deposition benchmarks required for fruit, which will be important since these may differ from leaves. Future studies should, therefore, investigate the use of reduced mancozeb dosages $(0.15 \times$ and $0.30 \times)$ under orchard conditions to determine the effect of weathering on efficacy and if fruit infections will be controlled.

The successful development of a biological efficacy benchmark model requires an effective pathogen inoculum production system, as well as an optimized postinoculation incubation protocol. This is challenging for a hemibiotroph such as $V$. inaequalis. Several aspects of the inoculum production and postinoculation protocols that were used in the current study were deemed essential for the successful establishment of the benchmark model. Firstly, our modified in vitro cellophane plate method published by Parker et al. (1995) consistently yielded conidia with a high germination percentage. This is not always possible when conidia are harvested from field collected lesions and if unsprayed orchards are not available to collect lesions from. Secondly, for postinoculation incubation, the inoculated plants were incubated during the first $48 \mathrm{~h}$ in the absence of light at the required leaf wetness period (100 to $95 \% \mathrm{RH})$ and temperature $\left(18^{\circ} \mathrm{C}\right)$. The dark period is deemed important since the hypersensitive host plant response, which inhibits pathogen infections, requires light. Therefore, in the absence of light, pathogen infections are likely more effective, thus resulting in higher infection levels than in the presence of light (Chandra-Shekara et al. 2006). Lastly, the continued incubation of seedlings at a high $\mathrm{RH}\left(70\right.$ to $\left.75 \% \mathrm{RH} 18^{\circ} \mathrm{C}\right)$ following the first 48-h postinoculation incubation period for the remainder of the experiment (7 days) was important. For example, it is known that the minimum relative humidity range for apple scab sporulation is between 60 and 70\%, whereas lesions may fail to develop at $\mathrm{RH}$ lower than the aforementioned range (Tomerlin and Jones 1983).

Another aspect of the successful development of a biological efficacy benchmark model is accurate disease quantification methods. For the qPCR analysis, it was important to use an internal control gene (mutated $E$. coli gene spiked into the DNA extraction buffer) to ensure that mancozeb and fluorescent pigment residues did not inhibit qPCR amplification. In our study, the extracted DNA required dilution for use in qPCR reactions in order to avoid inhibition. Inhibitors in DNA extracts are known to affect the reliability of qPCR quantifications (Daniell et al. 2012; McKee et al. 2015; Wang et al. 2017). For the TIRI assessment, it was important to reduce variability caused by environmental parameters (temperature and relative humidity) during image capturing; environmental conditions are known to influence the accuracy of TIRI measurements (Costa et al. 2013). This was achieved by calibrating the reference temperature of the FLIR infrared camera before evaluation of each trial.

In conclusion, this study determined $\mathrm{FPC}_{50}, \mathrm{FPC}_{75}$, and $\mathrm{FPC}_{90}$ benchmarks for apple leaves that can serve as a guideline to assess the efficacy of mancozeb sprays in apple orchards. Due to the high risk of apple scab, the $\mathrm{FPC}_{90}(0.34 \mathrm{FPC} \%)$ obtained with the qPCR quantification method should be considered as the benchmark deposition value that can be used in apple orchards. Evaluation of the biological efficacy of this benchmark under orchard conditions will be important in future studies. The qPCR quantification method is proposed as a robust method for quantifying disease levels in future studies aiming to develop benchmark models for other contact fungicides and mesosystemic and systemic fungicides against $V$. inaequalis. Our study is the first study to suggest that TIRI is not suitable for quantifying disease control obtained with fungicides since it does not differentiate between successful and unsuccessful infection sites. This is due to TIRI measuring a host response to infection, rather than pathogen growth in infected tissue.

\section{Acknowledgments}

We would like to thank the South African Apple and Pear Producer's Association (SAAPPA) for funding the project. We also thank Trevor Koopman (Agricultural Research Council, Infruitec-Nietvoorbij) for providing $V$. inaequalis cultures, and the Council for Scientific and Industrial Research (CSIR; Materials Science and Manufacturing group) for providing the thermal camera through the Robotic flagship project (Institute for Grape and Wine Science [IGWS]).

\section{Literature Cited}

Barbedo, J. G. 2013. Digital image processing techniques for detecting, quantifying and classifying plant diseases. Springerplus 2:660-671.

Blanca, M. J., Alarcón, R., Arnau, J., Bono, R., and Bendayan, R. 2017. Nonnormal data: Is ANOVA still a valid option? Psicothema 29:552-557.

Bowen, J. K., Mesarich, C. H., Bus, V. G. M., Beresford, R. M., Plummer, K. I. M. M., and Templeton, M. D. 2011. Venturia inaequalis: The causal agent of apple scab. Mol. Plant Pathol. 12:105-122.

Chandra-Shekara, A. C., Gupte, M., Navarre, D., Raina, S., Raina, R., Klessig, D., and Kachroo, P. 2006. Light-dependent hypersensitive response and resistance signaling against Turnip Crinkle Virus in Arabidopsis. Plant J. 45:320-334.

Costa, J. M., Grant, O. M., and Chaves, M. M. 2013. Thermography to explore plant-environment interactions. J. Exp. Bot. 64:3937-3949.

Cuthbertson, A. G. S., and Murchie, A. K. 2003. The impact of fungicides to control apple scab (Venturia inaequalis) on the predatory mite Anystis baccarum and its prey Aculus schlechtendali (apple rust mite) in Northern Ireland Bramley orchards. Crop Prot. 22:1125-1130.

Daniell, T. J., Davidson, J., Alexander, C. J., Caul, S., and Roberts, D. M. 2012. Improved real-time PCR estimation of gene copy number in soil extracts using an artificial reference. J. Microbiol. Methods 91:38-44.

Daniëls, B., De Landtsheer, A., Dreesen, R., Davey, M. W., and Keulemans, J. 2012. Real-time PCR as a promising tool to monitor growth of Venturia spp. in scab-susceptible and -resistant apple leaves. Eur. J. Plant Pathol. 134: 821-833.

Delalieux, S., van Aardt, J., Keulemans, W., Schrevens, E., and Coppin, P. 2007. Detection of biotic stress (Venturia inaequalis) in apple trees using hyperspectral data: Non-parametric statistical approaches and physiological implications. Eur. J. Agron. 27:130-143.

Dewdney, M., Charest, J., Paulitz, T., and Carisse, O. 2003. Multivariate analysis of apple cultivar susceptibility to Venturia inaequalis under greenhouse conditions. Can. J. Plant Pathol. 25:387-400.

Dorr, G. J., Wang, S., Mayo, L. C., McCue, S. W., Forster, W. A., Hanan, J., and $\mathrm{He}, \mathrm{X}$. 2015. Impaction of spray droplets on leaves: Influence of formulation and leaf character on shatter, bounce and adhesion. Exp. Fluids 56:143.

Gullino, M. L., Tinivella, F., Kemmit, G. M., Bacci, L., and Sheppard, B. 2010. Mancozeb, past, present, and future. Plant Dis. 94:1076-1087.

Gusberti, M., Patocchi, A., Gessler, C., and Broggini, G. A. L. 2012. Quantification of Venturia inaequalis growth in Malus $\times$ domestica with quantitative real-time polymerase chain reaction. Plant Dis. 96:1791-1797.

Holb, I. J. 2008. Timing of first and final sprays against apple scab combined with leaf removal and pruning in organic apple production. Crop Prot. 27:814-822.

Juste, F., Sanchez, S., Ibanez, R., Val, L., and Garcia, C. 1990. Measurement of spray deposition and efficiency of pesticide application in citrus orchards. J. Agric. Eng. Res. 46:187-196.

Landers, A. J. 2010. Nozzle selection and calibration. Pages 43-66 in: Effective Vineyard Spraying; in Effective Spraying. A. J. Landers, ed. First, Geneva, NY.

MacHardy, W. E. 1996a. Environmental and biological factors that influence foliar infection during continuous wetness. Pages 342-360 in: Apple Scab: Biology, Epidemiology, and Management, 1st ed. American Phytopathological Society, St. Paul, MN.

MacHardy, W. E. 1996b. Sanitation practices: Strategies and potential in apple scab IPM. Pages 434-455 in: Apple Scab: Biology, Epidemiology, and Management, 1st ed. American Phytopathological Society, St. Paul, MN.

MacHardy, W. E. 1996c. Environmental and biological factors that influence the incubation period. Pages 379-382 in: Apple Scab: Biology, Epidemiology, and Management, 1st ed. American Phytopathological Society, St. Paul, MN. 
MacHardy, W. E., and Gadoury, D. M. 1986. Pattern of ascospore discharge by Venturia inaequalis. Phytopathology 76:985-990.

McCallan, S. E. 1949. The nature of the fungicidal action of copper and sulfur. The New York Botanical Garden 15:629-643.

McKee, A. M., Spear, S. F., and Pierson, T. W. 2015. The effect of dilution and the use of a post-extraction nucleic acid purification column on the accuracy, precision, and inhibition of environmental DNA samples. Biol. Conserv. 183: 70-76.

Moein, S., Mazzola, M., Spies, C. F. J., and McLeod, A. 2019. Evaluating different approaches for the quantification of oomycete apple replant pathogens, and their relationship with seedling growth reductions. Eur. J. Plant Pathol. 154:243-257.

Oerke, E. C., Fröhling, P., and Steiner, U. 2011. Thermographic assessment of scab disease on apple leaves. Precis. Agric. 12:699-715.

Parisi, L., and Lespinasse, Y. 1996. Pathogenicity of Venturia inaequalis strains of race 6 on apple clones (Malus sp.). Plant Dis. 80:1179-1183.

Parisi, L., Lespinasse, Y., Guillaumes, J., and Krüger, J. 1993. A new race of Venturia inaequalis virulent to apples with resistance due to the Vf Gene. Phytopathology 83:533-537.

Parker, D. M., Hilber, U. W., Bodmer, M., Smith, F. D., Yao, C., and Koller, W. 1995. Production and transformation of conidia of Venturia inaequalis. Phytopathology 85:87-91.

Rebel, P. 2019. Optimizing pesticide spraying in high density apple orchards in South Africa, using Venturia inaequalis as model pathogen. M.Sc. thesis. Stellenbosch University, South Africa.

Rossouw, C. J. 2016. Mancozeb rainfastness and residue thresholds for control of Venturia inaequalis. M.Sc. thesis. Stellenbosch University, South Africa. http:// scholar.sun.ac.za/handle/10019.1/98315

Rossouw, C. J., Fourie, P. H., Van Zyl, J. G., Hoffman, J. E., and Mcleod, A. 2018. Rainfastness of mancozeb on apple seedlings determined through deposition quantification of mancozeb residue and a fluorescent pigment. Crop Prot. 106:93-102.

Schnabel, G., and Jones, A. L. 2001. The $14 \alpha$-Demethylase (CYP51A1) gene is overexpressed in Venturia inaequalis strains resistant to myclobutanil. Phytopathology 91:102-110.

Schutte, G. C., Kotze, C., Gideon van Zyl, J., and Fourie, P. H. 2012. Assessment of retention and persistence of copper fungicides on orange fruit and leaves using fluorometry and copper residue analyses. Crop Prot. 42:1-9.

Schwabe, W. F. S. 1976. Tolerance of Venturia inaequalis to benzimidazole fungicides and dodine in South Africa. Phytophylactica 9:47-54.
Schwabe, W. F. S. 1979. Changes in scab susceptibility of apple leaves as influenced by age. Phytophylactica 11:53-56.

Schwabe, W. F. S. 1980. Wetting and temperature requirements for apple leaf infection by Venturia inaequalis in South Africa. Phytophylactica 12:69-80.

Stensvand, A., Gadoury, D. M., Amundsen, T., Semb, L., and Seem, R. C. 1997. Ascospore release and infection of apple leaves by conidia and ascospores of Venturia inaequalis at low temperatures. Phytopathology 87:1046-1053.

Sutton, T. B., Aldwinckle, H. S., Agnello, M. A., and Walgenbach, J. F. 2014. Compendium of Apple and Pear Diseases and Pests, 2nd ed. American Phytopathological Society, St. Paul, MN.

Sutton, T. B., and Unrath, C. R. 1988. Evaluation of the tree- row- volume model for full season pesticide application on apples. Plant Dis. 72:629-632.

Tomerlin, J. R., and Jones, A. 1983. Effect of temperature and relative humidity on the latent period of Venturia inaequalis in apple leaves. Phytopathology 73: 51-54.

Turner, M. L., MacHardy, W. E., and Gadoury, D. M. 1986. Germination and appressorium formation by Venturia inaequalis during infection of apple seedling leaves. Plant Dis. 70:658-661.

Underdown, R. S., Sivasithamparam, K., and Barbetti, M. J. 2008. Inhibition of the pre- and postinfection processes of Plasmopara viticola on Vitis vinivera leaves by one protectant and four systemic fungicides. Australas. Plant Pathol. 37: 335-343.

Usak, V. I. H. 2015. Copper and copper-containing pesticides: Metabolism, toxicity and oxidative stress. J. Vasyl Stefanyk Precarpathian Natl. Univ. 2:38-50.

van Zyl, J. G., Fourie, P. H., and Schutte, G. C. 2013. Spray deposition assessment and benchmarks for control of Alternaria brown spot on mandarin leaves with copper oxychloride. Crop Prot. 46:80-87.

van Zyl, J. G., Sieverding, E. G., Viljoen, D. J., and Fourie, P. H. 2014. Evaluation of two organosilicone adjuvants at reduced foliar spray volumes in South African citrus orchards of different canopy densities. Crop Prot. 64:198-206.

van Zyl, S. A., Brink, J. C., Calitz, F. J., and Fourie, P. H. 2010. Effects of adjuvants on deposition efficiency of fenhexamid sprays applied to Chardonnay grapevine foliage. Crop Prot. 29:843-852.

Wang, H., Qi, J., Xiao, D., Wang, Z., and Tian, K. 2017. A re-evaluation of dilution for eliminating PCR inhibition in soil DNA samples. Soil Biol. Biochem. 106: 109-118.

Wong, F. P., and Wilcox, W. F. 2001. Comparative physical modes of action of azoxystrobin, mancozeb, and metalaxyl against Plasmopara viticola (grapevine downy mildew). Plant Dis. 85:649-656. 